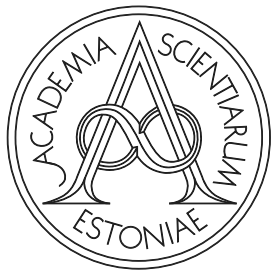

Proceedings of the Estonian Academy of Sciences, $2021,70,4,540-548$

https://doi.org/10.3176/proc.2021.4.23

Available online at www.eap.ee/proceedings

MATERIALS ENGINEERING

\title{
Tailoring the microstructure and tribological properties in commercially pure aluminium processed by High Pressure Torsion Extrusion
}

\author{
Babak Omranpour a,b,c*, Lembit Kommela , Fjodor Sergejeva, Julia Ivanisenko ${ }^{\mathrm{d}}$, Maksim Antonov ${ }^{\mathrm{a}}$, \\ Marco A. L. Hernandez-Rodriguez ${ }^{\mathrm{e}}$ and Edgar Garcia-Sanchez ${ }^{\mathrm{e}}$
}

\begin{abstract}
${ }^{a}$ Department of Mechanical and Industrial Engineering, Tallinn University of Technology (TalTech), 19086 Tallinn, Estonia
b Surface Engineering and Nanostructured Materials Research Group, Department of Chemical and Materials Engineering, Complutense University of Madrid (UCM), Av. Complutense, 28040 Madrid, Spain

${ }^{c}$ Hydrogen Research Institute, University of Québec in Trois-Rivières (UQTR), 3351 des Forges, Trois-Rivières G9A 5H7, Canada

${ }^{\mathrm{d}}$ Institute of Nanotechnology (INT), Karlsruhe Institute of Technology (KIT), 76021 Karlsruhe, Germany

e Facultad de Ingeniería Mecánica y Eléctrica (FIME), Universidad Autónoma de Nuevo León (UANL), 66455 San Nicolás de los Garza, Mexico
\end{abstract}

Received 18 June 2021, accepted 29 June 2021, available online 17 November 2021

(C) 2021 Authors. This is an Open Access article distributed under the terms and conditions of the Creative Commons AttributionNonCommercial 4.0 International License (http://creativecommons.org/licenses/by-nc/4.0/).

\begin{abstract}
High Pressure Torsion Extrusion (HPTE) as a novel approach in mechanical nanostructuring of metallic materials and alloys has the potential to be utilized in industrial applications due to its unique features in fabricating bulk-nanostructured materials with enhanced mechanical and functional properties. Three different HPTE regimes based on the extrusion speed of the punch $(\mathrm{v}, \mathrm{mm} / \mathrm{min})$ and rotational speed of the die $(\omega, \mathrm{rpm})$ were used in this work: $\mathrm{v} 7 \mathrm{w} 1, \mathrm{v} 1 \mathrm{w} 1$, and $\mathrm{v} 1 \mathrm{w} 3$. The grain refinement obtained by this technique was outstanding since the initial grain size of $120 \mu \mathrm{m}$ in annealed conditions was reduced to the final grain size of $0.7 \mu \mathrm{m}$ in v1w3 in merely one pass of extrusion; however, each regime showed a different level of grain refinement depending on the imposed strain. Examination of the tribological properties by reciprocal wear testing in dry conditions revealed no significant change in the coefficient of friction; nevertheless, the mechanism of the wear from adhesion shifted to abrasion and the amount of displaced volume decreased. This modification is associated with the improvement of hardness and the reduction of plasticity in materials that confined the plastic shearing. Increasing the induced strain by changing the HPTE regimes decreased the overall displaced volume and reduced the built-up edge around the wear track.
\end{abstract}

Key words: mechanical nanostructuring, microstructural evolution, wear resistance, friction coefficient.

\section{INTRODUCTION}

Nanostructured materials have demonstrated outstanding features due to the high surface-to-volume ratio in engineering applications. Mechanical nanostructuring techniques have made it possible to fabricate nanostructured materials with higher strength and superior mechanical and functional properties [1]. Enhancement of hardness and yield strength are the main outcomes of such pro-

\footnotetext{
${ }^{*}$ Corresponding author, omranpou@uqtr.ca
}

cessing techniques. In this regard, several techniques have been developed and studied to enhance the mechanical and functional properties of metals and alloys [1]. Severe Plastic Deformations (SPD), among other traditional methods, are famous for their impact on grain refinement and their contribution to the enhancement of mechanical properties [2]. It is openly admitted that harder materials, in general, provide lesser wear and a lower friction coefficient [3]. Several studies evaluated the influence of SPD techniques such as High-Pressure Torsion (HPT) [4], Equal Channel Angular Pressing (ECAP) [5], and Accumulative 
Roll Bonding (ARB) [6] on the wear and friction coefficient. The enhancement of wear resistance in SPD induced materials is a controversial subject among scientists $[7,8]$. In the case of aluminium alloys, some studies showed an improvement in the wear resistance of the processed samples [5,9], while others reported a reduction in the wear resistance after processing $[10,11]$. The latest studies evaluated the impact of a novel technique called High-Pressure Torsion Extrusion (HPTE) on the grain refinement, hardness, hydrogen storage, and wear resistance of materials [12-14]. This paper intends to explore the connection between the microstructural refinement and the tribological properties of aluminium 1050 processed by HPTE.

\section{MATERIALS AND METHODS}

\subsection{HPTE processing}

Figure 1 demonstrates the die model and the assembled configuration of HPTE [15]. As shown in this figure, the HPTE is composed of an upper die, which is fixed, and a lower die that is rotated by an electromotor. Samples are inserted through the upper die, extruded by a punch, and then exit through the lower die. The deformation zone is located between the upper die and lower die where the materials receive a cycle of expansion and extrusion along with torsion. Equation 1 shows the equivalent strain in
HPTE where D0, D1, and D2 are the diameters of the internal channels equal to $12,14,10.6 \mathrm{~mm}$, respectively; $\mathrm{R}$ is the distance from the centre at the cross-section of the sample; $v$ is the extrusion speed, and $\omega$ is the rotational speed.

Equation 1: Equivalent strain obtained by HPTE in one pass of extrusion

$$
\varepsilon_{\mathrm{HPTE}}=2 \ln \frac{\mathrm{D} 1}{\mathrm{D} 0}+2 \ln \frac{\mathrm{D} 1}{\mathrm{D} 2}+\frac{2 \pi \cdot \omega \cdot \mathrm{R} \cdot \mathrm{D} 1}{\sqrt{3} \cdot v \cdot \mathrm{D} 2} .
$$

The two process parameters of extrusion speed (v), and rotational speed $(\omega)$ influence the amount of strain and hence, the grain refinement of materials. More details about the die geometry and the process can be found elsewhere $[12,16]$. Because of the effect of torsion, materials will experience a gradient distribution of strain and thereby, a gradient distribution in hardness and grain refinement at the cross-section of the processed samples. Increasing the ratio of $\omega / v$ in HPTE increases the amount of strain imposed on the material, and accordingly, enhances the grain refinement [12].

\subsection{Materials and characterization techniques}

Commercially pure aluminium (CP-Al 1050) with the chemical composition of $\mathrm{Al}>99.5 \%, \mathrm{Fe}<0.20 \%$, $\mathrm{Si}<$ $0.15 \%, \mathrm{Cu}<0.05, \mathrm{Mg}<0.02$ (wt.\%) was annealed at

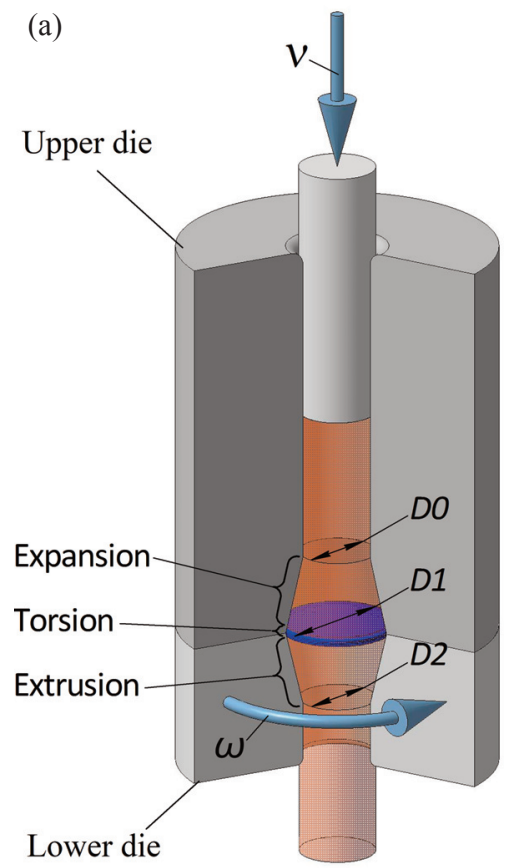

(b)

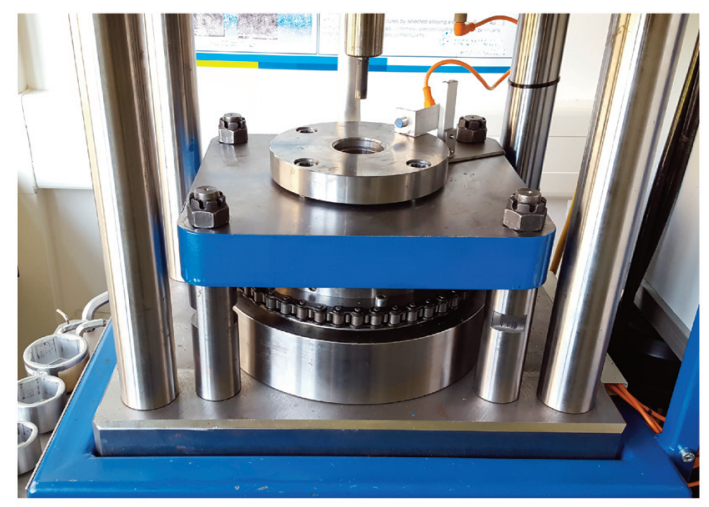

Fig. 1. HPTE die. (a) 3D illustration of the die and the channels; (b) the assembled configuration. 
$350{ }^{\circ} \mathrm{C}$ for $30 \mathrm{~min}$ and then processed by HPTE. Three different HPTE regimes were selected for processing of materials: $\mathrm{v}=7 \mathrm{~mm} / \mathrm{min}, \omega=1 \mathrm{rpm}(\mathrm{v} 7 \mathrm{w} 1) ; \mathrm{v}=1 \mathrm{~mm} / \mathrm{min}$, $\omega=1 \mathrm{rpm}(\mathrm{v} 1 \mathrm{w} 1) ; \mathrm{v}=1 \mathrm{~mm} / \mathrm{min}, \omega=3 \mathrm{rpm}(\mathrm{v} 1 \mathrm{w} 3)$. One sample was kept unprocessed in annealed conditions as a reference. The processed samples were cut, sectioned, and prepared for wear testing. A "Buehler Micromet-5104" tester with a load of $0.2 \mathrm{~kg}$ and a dwell time of $15 \mathrm{~s}$ was employed to perform the micro-indentation. Eleven points with equal distances from each other along the diameter at the cross-section of the specimens were selected to expose to indentation. Three specimens in each group were tested to ensure the consistency of the results. The reciprocal wear testing was conducted by a CETR/Bruker $U M T-2$ tribometer on the cross-sectional surface of the samples in reciprocal, dry sliding conditions. As specified earlier, the processed materials have a gradient distribution of hardness and microstructure at the cross-section from edge to centre. Therefore, different wear tests were performed at three different radii to assess the impact of torsion induced gradient on the wear resistance of materials. These wear tests were carried out in the following zones: centre zone $(\mathrm{r} \approx 0.5 \mathrm{~mm})$, mid-radius zone $(\mathrm{r} \approx 2.5 \mathrm{~mm})$, and the edge zone $(\mathrm{r} \approx 4.5 \mathrm{~mm})$. Figure 2 demonstrates the location of the wear tests on the surface of the specimens.

Bearing steel balls of chrome steel (100CR6, Redhill balls ${ }^{\mathrm{TM}}$ ) with a diameter of $3 \mathrm{~mm}$ and a Vickers hardness of $63 \pm 3$ HRC were utilized as the counter-surface for wear testing of the samples. The reciprocal sliding wear tests were performed at room temperature $\left(21^{\circ} \mathrm{C}\right)$ with a relative humidity of $50 \%$. All samples were examined under a load of $0.2 \mathrm{~N}$, and each test was repeated three times. The wear tests were conducted at a frequency of $3 \mathrm{~Hz}$ and an amplitude of $1 \mathrm{~mm}$ with an average sliding

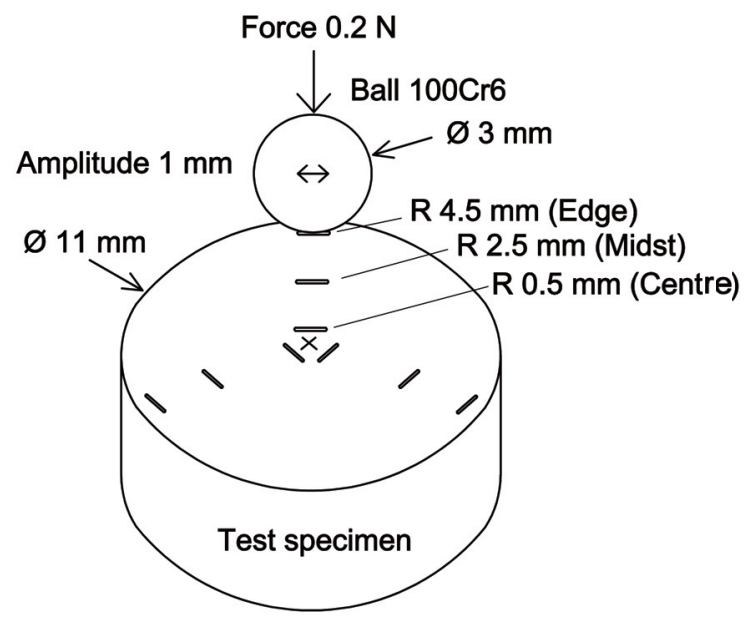

Fig. 2. Demonstration of the tribosystem and the location of the wear tracks on the surface of the specimen.
Table 1. Mechanical properties of the interacting surfaces in the tribosystem

\begin{tabular}{lcc}
\hline & $\begin{array}{c}\text { AA1050-O } \\
\text { workpiece }\end{array}$ & 100Cr6 steel balls \\
\hline Yield strength [MPa] & 41 & 586 \\
Ultimate strength [MPa] & 108 & 824 \\
Modulus of elasticity [GPa] & 71 & 203 \\
Poisson's ratio & 0.33 & 0.29
\end{tabular}

speed of $6 \mathrm{~mm} / \mathrm{s}$ for a total period of $100 \mathrm{~min}$. The mean and maximum values of contact pressure were $\sim 0.16 \mathrm{GPa}$ and $\sim 0.25 \mathrm{GPa}$ respectively for the Hertzian initial point contact in the present tribosystem. The volume loss in the wear tracks was measured using a Bruker Contour GT$\mathrm{KO}+$ optical profilometer. The samples were cleaned by ethanol and compressed air before and after the wear tests. The microstructural analysis of the samples was performed by means of FEI Quanta 3D scanning electron microscope (SEM) operating at $20 \mathrm{kV}$. The EBSD images were obtained by using the orientation imaging (OIM) software. Material properties of the aluminium specimens and steel balls are shown in Table 1 .

\section{RESULTS}

\subsection{Mechanical and microstructural evolution}

The results of microstructural analysis of the samples by SEM and EBSD are displayed in Fig. 3. The annealed specimen is represented in Fig. 3a, and the processed specimens are shown by orientation image mapping in Fig. 3b, c, d, $\mathrm{e}, \mathrm{f}$, and $\mathrm{g}$. The EBSD images in the left column were adopted from the centre of the cross-section of the HPTE specimens $(\mathrm{r} \approx 0.5 \mathrm{~mm})$, and the ones in the right column were taken from the edge zone (where the highest amount of strain was imposed on the materials; $r \approx 4.5 \mathrm{~mm}$ ). The grain size in the annealed specimen with an average value of $120 \mu \mathrm{m}$ (Fig. 3a) considerably decreased in size after processing. The finest microstructure was obtained in v1w3 at the edge zone with an average grain size of $0.7 \mu \mathrm{m}$ (Fig. 3g).

The Micro-hardness graph is represented in Fig. 4. As can be seen in this graph, there is a remarkable enhancement in the hardness. All the processed samples demonstrated a V-shape distribution as a result of torsion that was imposed on the material. The initial hardness with an average value of $29 \mathrm{HV} 0.2$ in the annealed sample increased to the highest value of $67 \mathrm{HV} 0.2$ in v1w3 at the edge zone. Table 2 summarizes the results of ESBD analysis and hardness testing in each section of the samples with respect to the imposed strain. 


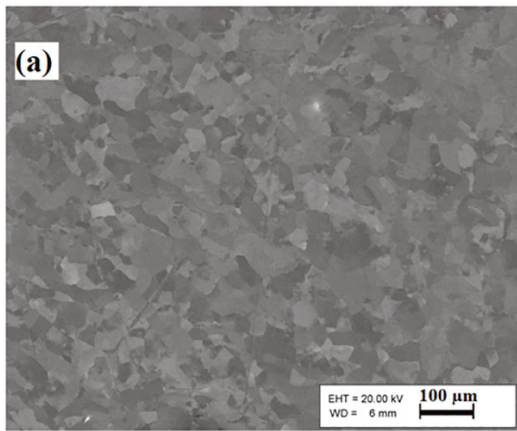

Annealed
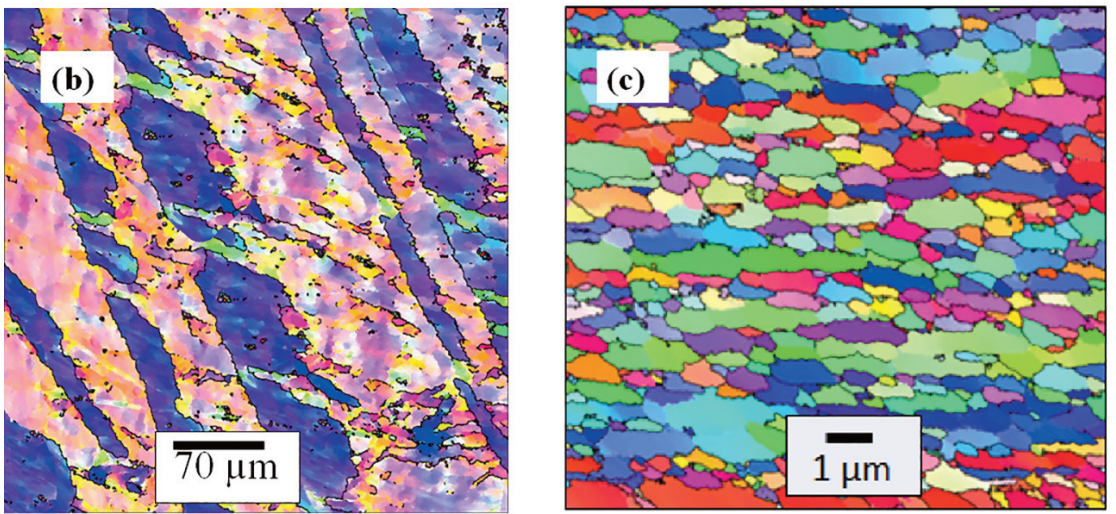

$\mathrm{v} 7 \mathrm{w} 1$
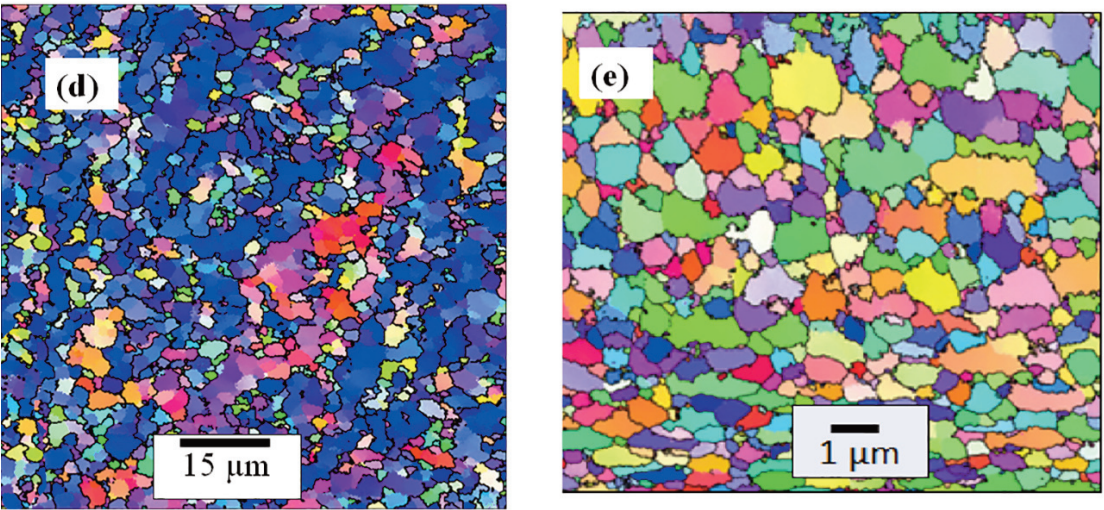

v1w1

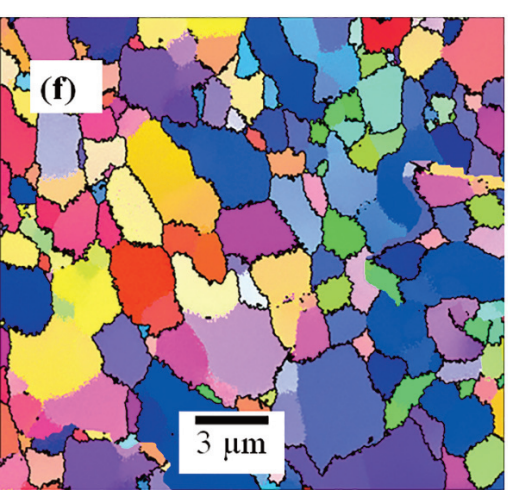

Centre

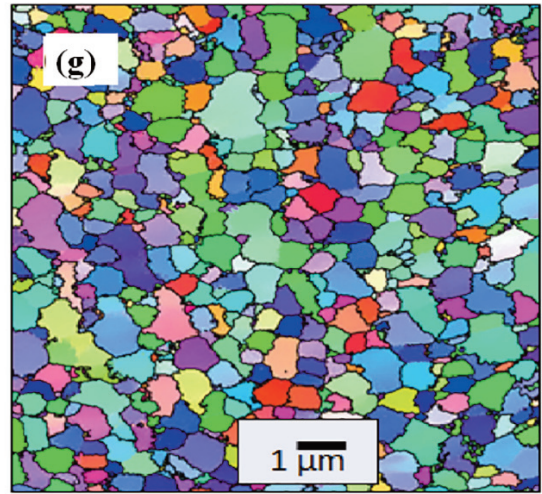

Edge

v1w3

Fig. 3. SEM/EBSD analysis of the microstructure of samples: (a) Initial specimen (annealed), (b,c) v7w1, (d,e) v1w1, and (f,g) v1w3. The left column of the EBSD images was taken from the central zone and the right ones were taken from the edge zone of the specimens. 


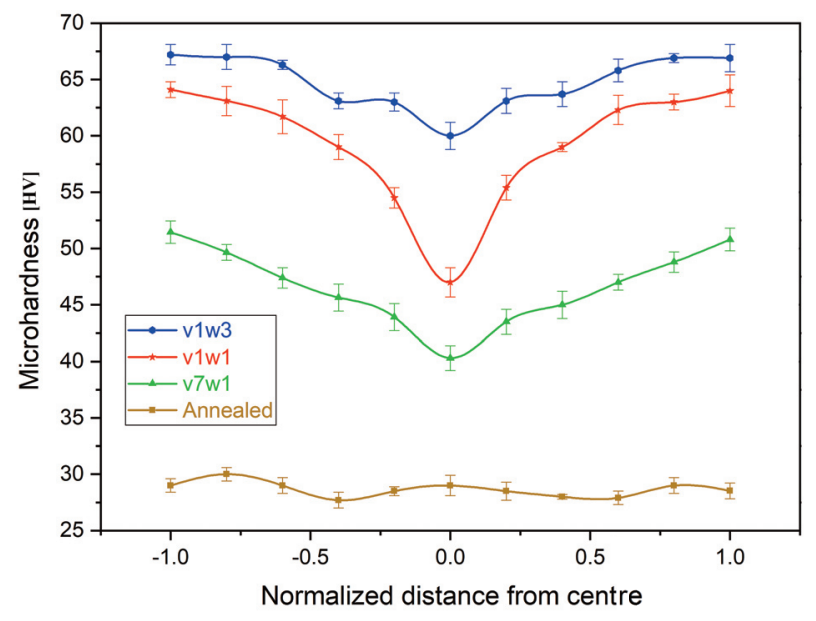

Fig. 4. Hardness evolution in the cross-section of HPTE specimens.

\subsection{Wear test}

Analysis of the wear performance showed that HPTE did not alter the coefficient of friction (COF) in the samples as this parameter in the annealed and processed samples was in the order of $0.31 \pm 0.03$. Figure 5 displays the COF graph with respect to time for the v1w3 specimen.

The results of investigations on the wear tracks by using a confocal microscope are collected in Table 3. Figure 6 shows an example of this analysis on the v1w1 specimen. This analysis is based upon the measurement of two parameters: the positive volume and the negative volume. The positive volume in this study refers to the volume of the material that was moved and relocated above the surface (above zero level) as a result of the sliding of the ball on the surface of the workpiece and the subsequent plastic shearing; such examples of positive volumes are the built-up edges or the compressed, accumu-

Table 2. Results of microstructure and hardness testing of the samples

\begin{tabular}{l|c|rrrrr|cc}
\hline & Annealed & \multicolumn{2}{c|}{ v7w1 } & \multicolumn{2}{c|}{ v1w1 } & \multicolumn{2}{c}{ v1w3 } \\
\hline Location & - & Centre & Edge & Centre & Edge & Centre & Edge \\
$\begin{array}{l}\text { Equivalent } \\
\text { strain [mm/mm] }\end{array}$ & n.a. & 0.9 & 3.9 & 0.9 & 22.4 & 0.9 & 65.5 \\
$\begin{array}{l}\text { Grain size } \\
{[\mu \mathrm{m}]}\end{array}$ & 120 & 110 & 1.4 & 10.1 & 0.9 & 2.0 & 0.7 \\
$\begin{array}{l}\text { Hardness } \\
{[\mathrm{HV} 0.2]}\end{array}$ & 29 & 40 & 51 & 47 & 64 & 60 & 67
\end{tabular}

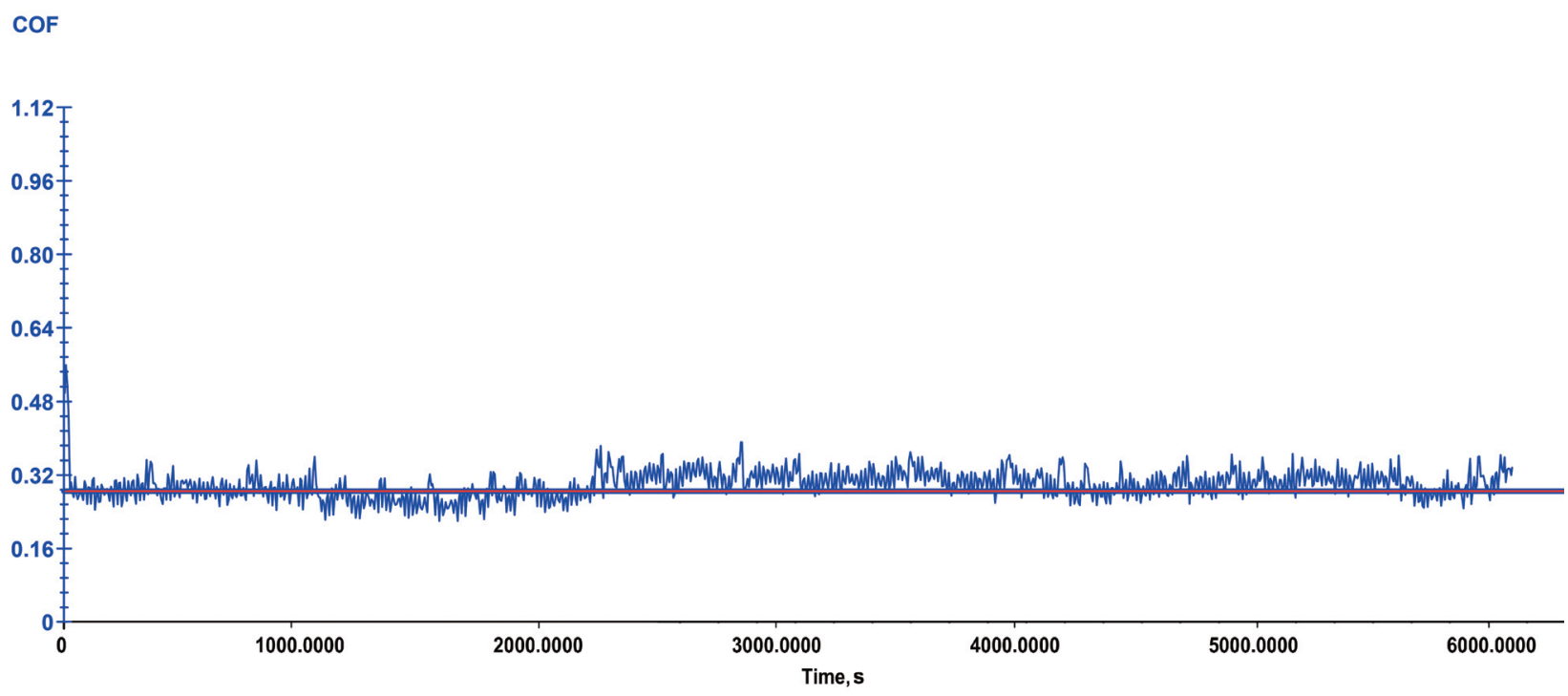

Fig. 5. Demonstration of the Coefficient of Friction (COF) versus time in the v1w3 specimen. 
Table 3. Results of the analysis on the wear tracks; all numbers are in the dimension of $\left[\mathrm{x}_{10} 0^{6} \mathrm{~m}^{3}\right]$

\begin{tabular}{l|ccc|ccccccccc}
\hline & \multicolumn{3}{|c|}{ Negative volume } & \multicolumn{3}{c|}{ Positive volume } & \multicolumn{3}{c}{$\begin{array}{c}\text { Net Missing Volume } \\
\text { (M.V.) }\end{array}$} & \multicolumn{3}{c}{$\begin{array}{c}\text { Total Displaced } \\
\text { Volume (D.V.) }\end{array}$} \\
\hline $\begin{array}{l}\text { Track } \\
\text { location }\end{array}$ & Centre & Midst & Edge & Centre & Midst & Edge & Centre & Midst & Edge & Centre & Midst & Edge \\
v1w3 & 1.12 & 1.37 & 1.28 & 0.04 & 0.01 & 0.05 & 1.08 & 1.36 & 1.23 & 1.16 & 1.38 & 1.33 \\
v1w1 & 3.01 & 5.06 & 6.15 & 0.50 & 0.14 & 0.35 & 2.51 & 4.92 & 5.80 & 3.51 & 5.20 & 6.50 \\
v7w1 & 4.60 & 5.72 & 6.85 & 1.75 & 1.22 & 0.90 & 2.85 & 4.50 & 5.95 & 6.35 & 6.94 & 7.75 \\
Annealed & 4.93 & 5.30 & 5.52 & 2.87 & 3.44 & 2.82 & 2.06 & 1.86 & 2.70 & 7.80 & 8.74 & 8.34
\end{tabular}
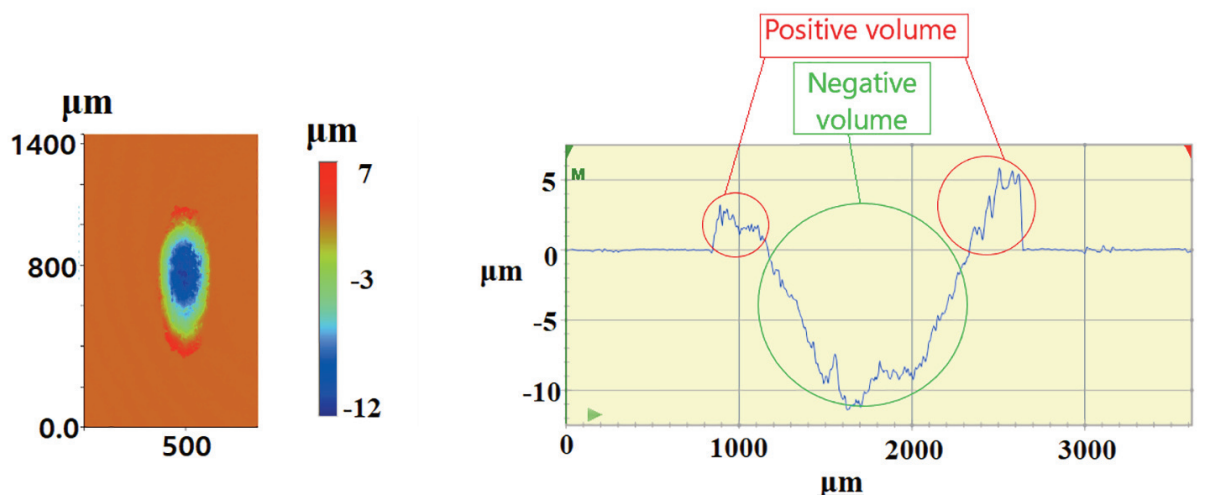

Fig. 6. Results of confocal microscopy analysis on the v1w1 specimen in the centre zone [14]. Left: 3D-profile analysis of the wear track. Right: cross-section of the wear track. The built-up edge was considered as the positive displaced volume, and the groove space as the negative volume.

lated debris materials around the wear track. The negative volume pertains to that part of the material below zero level which was worn/removed away and formed a groove on the surface. Based on the two aforementioned factors, two new parameters are defined here to better analyse and elaborate the wear behaviour of the materials: the net Missing Volume (M.V.), which is the difference between the negative and positive volumes, and the total Displaced Volume (D.V.), which is the sum of absolute values of positive and negative volumes. As indicated in Table 3, all processed samples showed a remarkable decrease in the amount of positive volume (built-up edge) around the wear track, and thereby decreasing the total amount of D.V.

\section{DISCUSSION}

Analysis of the wear properties of engineering materials is important to be considered in the serviceability and durability of their components. This fact becomes even more significant when designing nanostructured materials. Evaluation of the Coefficient of Friction (COF) is also an important feature in order to assess the performance of structural materials when sliding against each other; generally, a lower COF helps the material to show a better load-bearing capacity [7]. The present research studied the impact of a novel mechanical nanostructuring technique on the grain refinement of aluminium and the resulting evolution of hardness and tribological properties. The microstructural investigations by means of EBSD technique demonstrated a significant grain refinement after processing. It was revealed that the level of refinement was dependent on the selected regime. As mentioned above, HPTE is a combination of extrusion and torsion; the torsion-induced deformation has a remarkable influence on the grain refinement and materials' properties. The extrusion speed (v) and rotational speed $(\omega)$ along with the distance from the centre $(\mathrm{R})$ are the main parameters affecting the amount of strain, and hence, the properties (see Equation 1). Assessment of the microstructure of the processed samples revealed a gradient distribution in the grain size from centre to edge. Based on the results presented in Table 2, the average grain size measured by EBSD in the centre and in the edge zone of the processed samples showed a notable difference. For example, in the 
case of $\mathrm{v} 7 \mathrm{w} 1$, this difference was around $110 \mu \mathrm{m}$ in the centre versus $1.4 \mu \mathrm{m}$ in the edge. A similar pattern of change exists in the hardness values in the centre and the edge zone of samples. It should, however, be noted that the theoretical value of strain imposed on the central zone is the same in all samples $(\varepsilon=0.9)$ since there is no component of torsional strain in the centre, whereas the grain size and the hardness measured in the centre are different. This distinction can be explained by considering the phenomenon of gradient plasticity [17]. It was rationalized that plasticity can spread out from the origin of plastic deformation to the neighbouring regions and affect the deformation. In this scenario, the plastic deformation could spread out from the outer regions of samples into the central zone and affected the microstructure and mechanical properties [12]. As indicated earlier, the shear strain out of the centre of the samples can rise by increasing the ratio of $\omega / \mathrm{v}$. Therefore, the induced deformation by gradient plasticity increased in the order of $\mathrm{v} 7 \mathrm{w} 1, \mathrm{v} 1 \mathrm{w} 1$, and v1w3. As a result, the hardness and grain refinement in the centre enhanced in the same order. For instance, the initial hardness value of $29 \mathrm{HV}$ increased to 40, 47, $60 \mathrm{HV}$ in $\mathrm{v} 7 \mathrm{w} 1, \mathrm{v} 1 \mathrm{w} 1$, and $\mathrm{v} 1 \mathrm{w} 3$, respectively, despite receiving the same nominal strain in all cases.

Analysis of the tribological properties in the samples is even more complicated because of the contribution of several factors in the wear behaviour. The correlation between hardness and wear resistance is only one factor influencing the tribological behaviour of materials; many other parameters such as the normal load, sliding speed, initial temperature, and the thermal, mechanical, and chemical properties of the material may affect the tribosystem and change the wear behaviour [18]. According to the results of Table 3, the net missing volume (M.V.) did not decrease in $\mathrm{v} 1 \mathrm{w} 1$ and $\mathrm{v} 7 \mathrm{w} 1$ regimes; the only reduction of M.V. was detected in v1w3 where the highest hardness values and finest microstructure were achieved (see Figs 3 and 4). Nonetheless, all HPTE processed samples generated lower amounts of positive volume, and hence, lower displaced volume (D.V). This phenomenon is associated with increasing the hardness and resistance against the plastic shearing in the HPTE samples [14]. As shown in Table 2, the processed samples achieved higher hardness values as compared to the annealed one. In the case of the v1w3 regime, materials received the highest amount of strain, and accordingly, represented the highest resistance against plastic shearing. This fact can also be verified in Fig. 7. This figure illustrates the generated negative and positive volumes in each sample and each section graphically.

As shown in the graphs, the amount of positive volume decreased by increasing the plastic deformation whereas the only obvious change in the generated negative volume is in v1w3 regime. Decreasing the positive volume results in decreasing the total displaced volume. The displaced volume has a great contribution to the intensification of the adhesive wear. Considering this fact, the dry sliding wear test on the annealed sample (with the lowest hardness) made a thick layer of built-up edge around the wear track named as positive displaced volume. Thus, it can be inferred that a large portion of the wear in the annealed sample was formed by the mechanism of adhesion. Increasing the hardness diminished the positive volume and mitigated the adhesive wear, making the abrasion predominant in the wear. This transition of the adhesive wear to abrasive wear was reported earlier not only for aluminium [10] but also for other materials such as titanium where the adhesive wear in annealed con-
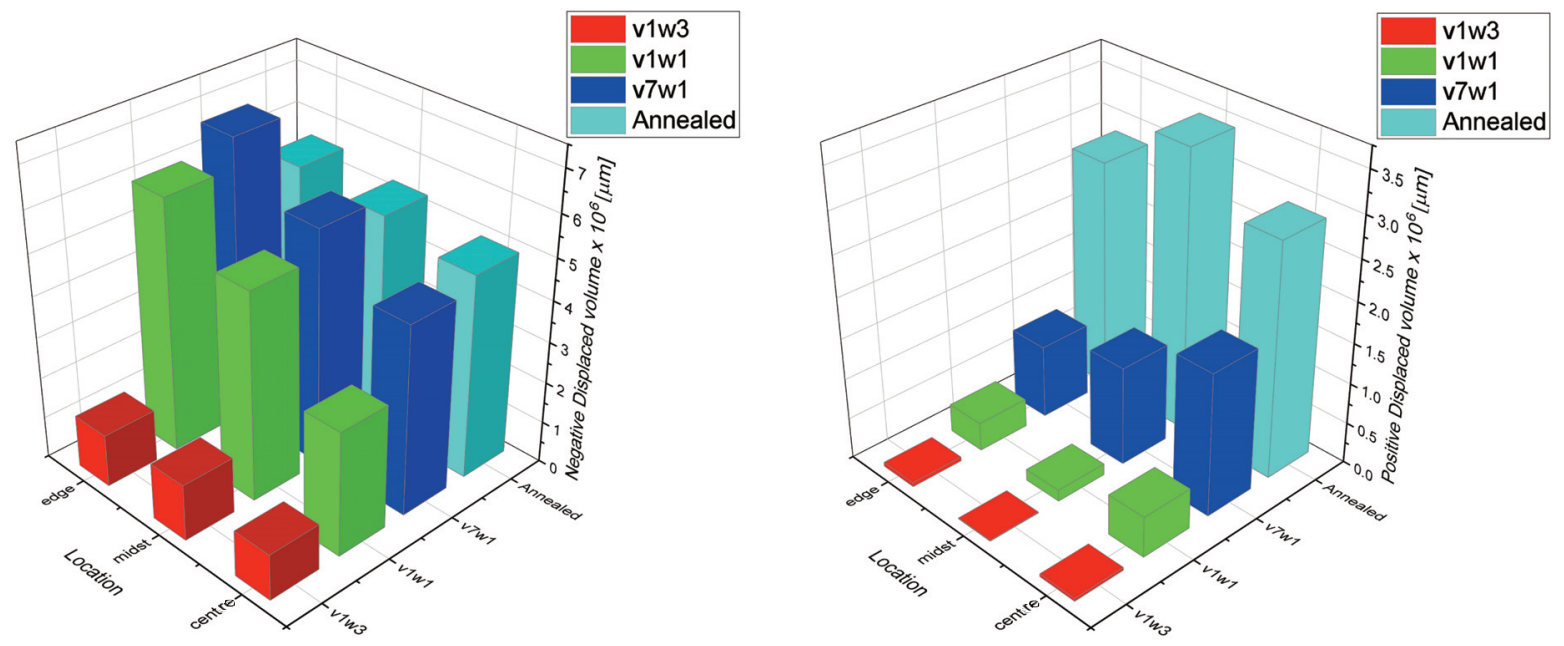

Fig. 7. The negative (left) and the positive (right) displaced volume generated by the dry sliding wear test on the annealed and processed samples. 
ditions with coarse grained microstructure shifted to abrasion/delamination in SPD processed materials [19].

Eventually, it should be outlined that different physical mechanisms may affect the wear and no universal model can apply to all situations [7]. In the current study, HPTE could successfully reduce the built-up edge around the wear track owing to its contribution to increasing the hardness and resistance of materials to plastic shearing. This resulted in decreasing the total displaced volume and generating less adhesive wear. More investigations are required to establish a firm analysis about the impact of this technique on the tribological properties of soft versus hard materials.

\section{CONCLUSIONS}

This research investigated the impact of High Pressure Torsion Extrusion (HPTE) on the grain refinement and tribological properties of aluminium AA-1050. The following outcomes can be drawn from this work:

HPTE could substantially refine the microstructure in aluminium. The initial grain size of $120 \mu \mathrm{m}$ decreased to $110,10.1,2.0 \mu \mathrm{m}$ in the centre, and to the finest size of $1.4,0.9,0.7 \mu \mathrm{m}$ in the edge zone of the samples by $\mathrm{v} 7 \mathrm{w} 1$, v1w1, and v1w3 regimes, respectively, in merely one extrusion.

Each HPTE regime imposed a varied distribution of strain - from centre to edge - under the influence of torsion, although the nominal strain value in the centre of all samples was identical. Nonetheless, the real imposed strain and the level of grain refinement in the centre differed in each sample because of the impact of gradient plasticity by which the central zone was affected from the neighbouring regions.

Analysis of dry sliding wear tests at the cross-section of the specimens showed that HPTE processing led to a reduction of adhesive wear. This fact corresponds to the enhancement of hardness and increasing of the resistance of materials against plastic shearing. As a result of the reduction of plastic shearing in the processed samples during the wear, less built-up edge was formed around the wear tracks.

\section{ACKNOWLEDGEMENTS}

The authors are grateful for the financial support from the Estonian Research Council (grant number PUTJD 1010, the Institutional Research Funding IUT-1929) and MSCACOFUND-2018-UNA4CAREER - grant No. 847635. Maksim Antonov acknowledges the research grant "DuraCer" MOBERA9 ETAG18012. This work was prepared upon an invitation to be submitted to the
Proceedings of the Estonian Academy of Sciences as an extended version of an article presentated at the "Modern Materials and Manufacturing Conference-2021". The support and advice of Dr Andrei Surženkov is truly appreciated. The publication costs of this article were covered by the Estonian Academy of Sciences and Tallinn University of Technology.

\section{REFERENCES}

1. Jung, A., Diebels, S. and Lach, E. Improved mechanical properties by nanostructuring - Specific considerations under dynamic load conditions. In Handbook of Mechanical Nanostructuring, vol 1. Wiley-VCH Verlag GmbH \& Co. KGaA, Weinheim, 2015, 181-209.

2. Kommel, L., Shahreza, B. O. and Mikli, V. Microstructure and physical-mechanical properties evolution of pure tantalum processed with hard cyclic viscoplastic deformation. Int. J. Refract. Met. Hard Mater, 2019, 83, 104983.

3. Semenov, V. I., Shuster, L. S., Huang, S. J., Rajendran, R., Chertovskikh, S. V. and Shibakov, V. G. Comparative evaluation of the tribological properties of low-and mediumcarbon steels after heat treatment and severe plastic deformation. Rev. Adv. Mater. Sci., 2016, 45, 28-35.

4. Edalati, K., Ashida, M., Horita, Z., Matsui, T. and Kato, H. Wear resistance and tribological features of pure aluminum and $\mathrm{Al}-\mathrm{Al}_{2} \mathrm{O}_{3}$ composites consolidated by high-pressure torsion. Wear, 2014, 310(1-2), 83-89.

5. Abd E1 Aal, M. I., E1 Mahallawy, N., Shehata, F. A., Abd El Hameed, M., Yoon, E. Y. and Kim, H. S. Wear properties of ECAP-processed ultrafine grained Al-Cu alloys. Mater. Sci. Eng. A, 2010, 527(16-17), 3726-3732.

6. Talachi, A. K., Eizadjou, M., Manesh, H. D. and Janghorban, K. Wear characteristics of severely deformed aluminum sheets by accumulative roll bonding (ARB) process. Mater. Charact., 2011, 62, 12-21.

7. Gao, N., Wang, C. T., Wood, R. J. K. and Langdon, T. G. Tribological properties of ultrafine-grained materials processed by severe plastic deformation. J. Mater. Sci., 2012, 47(12), 4779-4797.

8. Kommel, L., Põdra, P., Mikli, V. and Omranpour, B. Gradient microstructure in tantalum formed under the wear track during dry sliding friction. Wear, 2021, 466-467, 203573.

9. Zhang, Z., Hosoda, S., Kim, I. S. and Watanabe, Y. Grain refining performance for $\mathrm{Al}$ and $\mathrm{Al}-\mathrm{Si}$ alloy casts by addition of equal-channel angular pressed Al-5 mass\% Ti alloy. Mater. Sci. Eng. A, 2006, 425, 55-63.

10. Wang, C. T., Gao, N., Wood, R. J. K. and Langdon, T. G. Wear behavior of an aluminum alloy processed by equalchannel angular pressing. J. Mater. Sci., 2011, 46(1), 123-130.

11. Oh-Ishi, K., Horita, Z., Furukawa, M., Nemoto, M. and Langdon, T. G. Optimizing the rotation conditions for grain refinement in equal-channel angular pressing. Metall. Mater. Trans. A, 1998, 29A, 2011-2013.

12. Omranpour, B., Ivanisenko, Y., Kulagin, R., Kommel, L., Garcia Sanchez, E., Nugmanov, D., Scherer, T., Heczel, A. 
and Gubicza, J. Evolution of microstructure and hardness in aluminum processed by high pressure torsion extrusion. Mater. Sci. Eng. A, 2019, 762, 138074.

13. Omranpour, B. S., Kommel. L., Sanchez, E. G., Ivanisenko, Y. and Huot, J. Enhancement of hydrogen storage in metals by using a new technique in severe plastic deformations. Key Eng. Mater., 2019, 799, 173-178.

14. Omranpour, B., Kommel, L., Sergejev, F., Ivanisenko, J., Antonov, M., Hernandez-Rodriguez, M. A. L. and GarciaSanchez, E. Analysis of the reciprocal wear testing of Aluminum AA1050 processed by a novel mechanical nanostructuring technique. IOP Conf. Ser. Mater. Sci. Eng., 2021, 1140(1), 012051.

15. Ivanisenko, Y., Kulagin, R., Fedorov, V., Mazilkin, A., Scherer, T., Baretzky, B. and Hahn, H. High pressure torsion extrusion as a new severe plastic deformation process. Mater. Sci. Eng. A, 2016, 664, 247-256.

16. Omranpour, B., Kulagin, R., Ivanisenko, Y. and GarciaSanchez, E. Experimental and numerical analysis of HPTE on mechanical properties of materials and strain distribution. IOP Conf. Ser. Mater. Sci. Eng., 2017, 194.

17. Estrin, Y., Molotnikov, A., Davies, C. H. J. and Lapovok, R. Strain gradient plasticity modelling of high-pressure torsion. J. Mech. Phys. Solids, 2008, 56(4), 1186-1202.

18. Williams, J. A. Engineering tribology. Cambridge University Press, 2005.

19. La, P., Ma, J., Zhu, Y. T., Yang, J., Liu, W., Xue, Q. and Valiev, R. Z. Dry-sliding tribological properties of ultrafinegrained Ti prepared by severe plastic deformation. Acta Mater., 2005, 53, 5167-5173.

\section{Mikrostruktuuri ja triboloogiliste omaduste kohandamine kaubanduslikult puhtas alumiiniumis, mida töödeldakse kõrgsurve väändekstrusiooni teel}

\section{Babak Omranpour, Lembit Kommel, Fjodor Sergejev, Julia Ivanisenko, Maksim Antonov, Marco A. L. Hernandez-Rodriguez ja Edgar Garcia-Sanchez}

Uuringust selgub, et kõrgsurve väändekstrusiooni (HPTE) kui uudset meetodit metalsete materjalide ja sulamite mehaanilisel struktureerimisel on võimalik tööstuses edukalt rakendada. Kirjeldatud meetodil saab valmistada ülipeeneteralisi ja nanostruktuurseid materjale, millel on täiustatud mehaanilised ja funktsionaalsed omadused. Töös kasutati kolme erinevat režiimi, mis põhinevad stantsi ekstrudeerimise kiiruse (v, mm/min) ja stantsi pöörlemiskiiruse ( $\omega$, p/min) HPTE parameetritel v7w1, v1w1 ja v1w3. Selle tehnikaga oli teramõõtmete vähendamine silmapaistev, kuna esialgne tera suurus $120 \mu \mathrm{m}$ lõõmutatud tingimustes vähendati lõpliku tera suuruseks $0,7 \mu \mathrm{m}$ (v1w3) ainult ühe ekstrudeerimise tsükliga. Triboloogiliste omaduste uurimine kuivhõõrde tingimustes ei näidanud olulist hõõrdeteguri muutust, kuid kulumise mehhanism ja materjali nihutatud maht kuivhõõrdel muutusid. See modifikatsioon materjalides on seotud kõvaduse suurenemise ja plastilisuse vähenemisega sõltuvalt HPTE protsessi parameetritest. 